\title{
A BRIEF REVIEW OF THE FUSION-FISSION HYBRID REACTOR
}

BY

F. H, TENNEY

\section{PLASMA PHYSICS LABORATORY}

MASTER

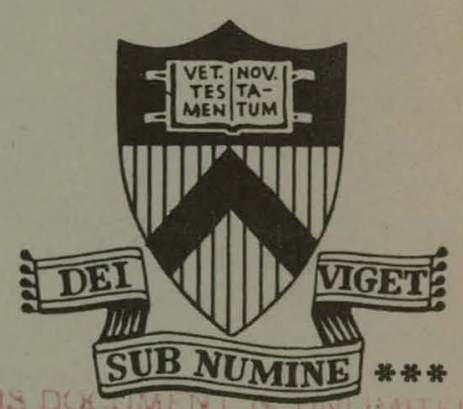

\section{PRINCETON \\ UNIVERSITY PRINCETON, NEW JERSEY}

This work was supported by U. S. Energy Research and Development Administration Contract $\mathrm{E}(11-1)-3073$. Reproduction, translation, publication, use and disposal, in whole or in part, by or for the United States Government is permitted. 


\section{DISCLAIMER}

This report was prepared as an account of work sponsored by an agency of the United States Government. Neither the United States Government nor any agency Thereof, nor any of their employees, makes any warranty, express or implied, or assumes any legal liability or responsibility for the accuracy, completeness, or usefulness of any information, apparatus, product, or process disclosed, or represents that its use would not infringe privately owned rights. Reference herein to any specific commercial product, process, or service by trade name, trademark, manufacturer, or otherwise does not necessarily constitute or imply its endorsement, recommendation, or favoring by the United States Government or any agency thereof. The views and opinions of authors expressed herein do not necessarily state or reflect those of the United States Government or any agency thereof. 


\section{DISCLAIMER}

Portions of this document may be illegible in electronic image products. Images are produced from the best available original document. 
NOTICE

This report was prepared as an account of work sponsored by the United States Government. Neither the United states nor the United States Energy Research and Development Administration, nor any of their employees, nor any of their contractors, subcontractors, or their employees, makes any warranty, express or implied, or assumes any legal liability or responsibility for the accuracy, completeness or usefulness of any information, apparatus, product or process disclosed, or represents that its use would not infringe privately owned rights.

Printed in the United States of America.

$$
\text { Available from }
$$

National Technical Information Service

U. S. Department of Commerce 5285 Port Royal Road

Springfield, Virginia 22151

Price: Printed Copy $\$ \ldots$; Microfiche $\$ 3.00$

NTIS

*Pages

$$
1-50
$$

$51-150$

$151-325$

326-500

501-1000
Selling Price

$\$ 4.00$

5.45

7.60

10.60

13.60 


\title{
A BRIEF REVIEW OF THE FUSION-FISSION HYBRID-REACTOR*
}

\author{
F. H. Tenney \\ Princeton Plasma Physics Laboratory \\ Princeton, N.J. 08540
}

\begin{abstract}
Much of the conceptual framework of present day fusion-fission hybrid reactors is found in the original work of the early 1950's. Present day motivations for development are quite different. The role of the hybrid reactor is discussed as well as the current activities in the development program.
\end{abstract}

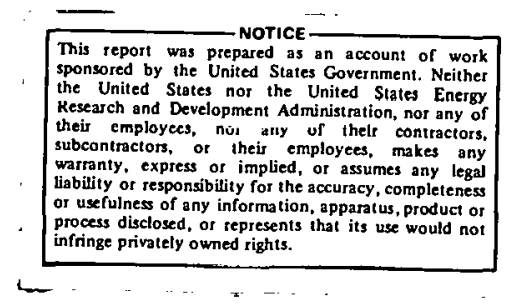

*Paper presented at the Second Topical Meeting on the Technology of Controlled Nuclear Fusion, September 21-23, 1976, Richland, Tashington. 
INTRODUCTION

The idea of a device in which both fusion events and fission events would occur is nearly as old as is the controlled thermonuclear research (CTR) program itself. An early problem for the CTR program seems to have been the production of sufficient tritium. Of the two fusion reactions under consideration, the DT and the DD reactions, the DT was favored because of its larger resonant crnss sestion occurring at lower energies. However to şustain a DT reactinr the triton consumed in each reaction must be replaced. Although the neutron released by the DT reaction was energetic (14 MeV), it appeared in the early 1950's to be an impossible task: for this single energetic neutron to produce at least one triton from the most promising source of tritium, the ${ }^{6} \mathrm{Li}(n, \mathrm{~T}) \mathrm{He}$ reaction. The addition of Be as a neutron multiplier in the early fusion blanket calculations did not salvage the situation. Therefore it is not surprising that the neutron multiplication then evident in the fissioning of uranium should be put to use in blankets surrounding the hypothetical fusion devices. So the concept of the hybrid reactor was born in the $1950^{\prime} \mathrm{s}$, more or less simultaneously in several places here and abroad. Illuminating "discussions of these early studies can be found in the excellent review articles by Leonard ${ }^{1}$ and by Lidsky ${ }^{2}$.

There was another problem that influenced the invention of hybrids and that was the problem of the production of plutonium for weapons development. The problem revolved around 
a neutron source. One approach was taken by the so-called Materials Testing Accelerator (MTA) program where the hope was to generate sufficient. "free neutrons" by bombarding suitable materials with very energetic particles. Out of this work came a proposal for a hybrid that displays much of the present thinking on hybrid technology, particularly those schemes using beam-driven plasmas. The similarity is strikingly revealed by a few quotations from the once secret proposal to the Atomic Energy Commission by Fred Powell dated October 6, 1953, then President of the California Research and Development Company of Livermore, California ${ }^{3}$. He has just referred to the DT reaction as a source of energetic neutrons.

"Investigation of this reaction to date has been essentially limited to the bombardment of heavy ice targets wherein only a minute fraction of the bombarded particles undergo the nuclear interaction; the major portion expending their energy in ionization of the target atoms.

"As an offshoot of our MTA work on conversion of accelerated charged particles to free neutrons and the utilization of these neutrons, consideration has been given to the foregoing reaction. It is evident that if a substantital portion of a triton or deuteron beam could be caused to undergo nuclear interaction with only a fraction lost to ionization, elastic scattering, and other side reactions, then the DT reaction might become a low-cost source of energetic free neutrons. The underlying principle of this proposal is the concept of bombarding a preionized tritium or deuterium target 
with a beam of accelerated deuterons or tritons. By this means incident beam energy losses through ionization could be minimized, leaving a substantial fraction of the incident beam energy available for nuclear interaction.

"A secondary but critical principle is the concept of a depleted uranium blanket surrounding the target chamber. By means of this blanket the energetic $14 \mathrm{MeV}$ neutrons from the DT reaction would cause fast fission and would thus be multiplied. Subsequentiy. the neutrons could be captured in U-238 to form plutonium or in $\mathrm{Li}^{6}$. to breed tritium. This concept of breeding in conjunction with a thermonuclear reaction is believed to be novel and capable of realizing breeding gains many times greater than the $0.3-0.5$ gain from the breeder reactor systems currently under consideration by the Commission." Here is the fissile fuel producing capability of the hybrid outlined and estimated!

Powe11 goes on to say "The problem of analyzing the interaction of an accelerated charged particle beam with a pre-ionized target material is analogous to a problem in stellar dynamics treated by $S$. Chandrasekhar. At the suggestion of Dr. R. F. Post of UCRL, Chandrasekhar:'s basic equations have been utilized in the prediction of neutron yields and energy loss to the nucleons and unbounded electrons in the ionized target plasma."

Chandrasekhar's problem, that is referred to above, concerned the gravitational interaction of a star moving through a cloud of stars in a galaxy. The analogy to the 
coulomb interactions between an energetic beam particle and a background plasma is precise and the lineal decendents ${ }^{4,5}$ of Chandrasekhar's solution have been used in more recent (and more accurate) calculations 6,7 of the neutron. yield from beam-driven plasmas.

Powell's summary of the proposal predicts:

"Beam - deuterons of approximately $200 \mathrm{keV}$ energy. Target - triton plasma of about $1 \mathrm{keV}$ 'temperature' and $10^{14}-10^{15}$ ions $/ \mathrm{cm}^{3}$ density. Production - 1 neutron of $14 \mathrm{MeV}$ energy per triton destroyed; 0.02-0.05 neutrons of $14 \mathrm{MeV}$ energy per incident deuteron; a maximum five fold multiplication of the $14 \mathrm{MeV}$ neutrons by fast fissions in depleted uranium; a maximum net fissionable material gain of 4."

These numbers have a ring of present day calculations. J. D. Lee's calculation ${ }^{8}$ of $233 \mathrm{MeV}$ released and $4.4(\mathrm{n}, \gamma)$ reactions per $14 \mathrm{MeV}$ neutron injected into pure. $\mathrm{U}^{238}$ is entirely consistent with the above predictions. The optimum energy for deuterons to be injected into a tritium plasma was calculated by Dawson, et al. ${ }^{6}$ to be $180-250 \mathrm{kV}$ for plasma temperatures between 1 and $50 \mathrm{keV}$; however their estimate of the DT fusions per incident deuteron was about an order of magnitude lower than Powell's number for a plasma temperature of $1 \mathrm{keV}$. This discrepancy may reflect an optimistic disregard by Powell of the electron drag on the injected particles since he also says that "a source of major beam energy loss would be the energy transfor frum lhe beam to the plasma nucleons." Un 
this point Powell goes on to say that "the energy lost in this fashion will appear as plasma heating which may be of considerable assistance in maintaining a high plasma 'temperature'." This beam heating mechanism is precisely the model adopted for the various two-component plasma schemes that form the fusion heart of the toroidal hybrid reactors under study today.

Powel1. is also sensitive to the economic aspects of his predicted operation which if true would indicate that "The process under consideration by virtue of its unique breeding gain and energy production, is truly an attractive possibility for economic :production of both fissionable materials and power." He then hedges a little in continuing: "With the proposed reaction in its formative research stages, no estimates of investment costs or operating requirements have been made, but it appears that both might be considerably less than for alternative schemes. One therefore sees an opportunity, with modest initial investment, to achieve Iarge production of weapons material at greatly reduced unit costs with no dependence or foreign or domestic ore supplies."

Substitute "fissile fuel" or "power" for the words "weapons material" in the above quotation and it "would be possible to hear much the same words spoken today. Finally, Powell imagines a mirror machine as a possible device in which to realize a high temperature plasma. In a following rieport by Imhoff ${ }^{9}$ the idea is evaluated of injecting both the deuterons and the tritons into a high temperature plasma with a 
consequent lowering of injection energy to something like $50 \mathrm{kV}$. This is essentially the argument. for the colliding beam torus $^{10}$ of recent vintage.

The difference between driven and thermonuclear plasmas was also appreciated for as Imhoff wrote: "The primary difference between the controlled and driven thermonuclear reaction lies in the conditions imposed upon the energy balance. The controlled thermonuclear reaction system depends primarily upon .the energy released by the thermonuclear reaction to maintain the system temperature once it has been initially created... the driven thermonuclear system relaxes this requirement by allowing additional amounts of energy to be added to the system continuously or intermittently by the injection of the particles at reaction energies."

Thus over twenty years ago most of the advantages claimed for hybrid systems were pointed out: The .enhanced breeding of fissile materlal and tritium, net power production at relaxed plasma conditions relative to a pure fusion device, and the conservation of uranium ores. And much of the physics of beam injected plasmas was also appreciated. What happened to these early efforts born and essentially dying in secret? The discovery of abundant domestic uranium ores, the adequate production of plutonium.by fission reactors and the discovery of the fast $(n, 2 n)$ tritium producing reaction in $\mathrm{Li}^{7}$ all acted to remove the incentive to pursue hybrid ideas. Of perhaps equal significance was the inability for anyone to produce a hlgh temperature plasma that would last for an interesting 
length of time. Suffice it to say that by 1958 when the CTR effort was declassified the hybrid ideas were at best laid aside and at worst forgotten. The recent thinking about hybrid has been, in fact quite independent of the early work. The motivations are quite different.

THE HYBRID ISSUE

The hybrid issuo io coocntially an cconomic issue: how will the cost of clectricity be affected by the use of hybrid devices? This is not a simple question and there is no definitive answer today. But there is a sense of urgency about the issue because of the perceived growth in demand for electrical power and the perceived difficulty in obtaining the fuel to meet that demand whether the fuel be fossil or nuclear. An energy strategy that has received a great deal of study assumes the increase in demand for electrical power will be met in the near future by fission reactors of the thermal converter type and that a fast fission breeder will be developed to assume the burden of electric power production before the reserves of moderate cost uranium are used up. 11,12 Some current projections 12,13 show the fast breeder meëting half the electric power demand by around the year 2030 and the thermal converters, in the course of their power generation, having been" able, to generate about three times the amount of plutonium necessary for the initial construction inventory of the breeders. The difficulty is that some 5 to 8 million short 
tons of $\mathrm{U}_{3} \mathrm{O}_{8}$ will have been. required to fuel the thermal converters over this span of time with at least half of this tonnage of necessity coming from the low grade Chattanooga Shale type of reserves at a price of perhaps $\$ 50-\$ 150$ per pound of. $\mathrm{U}_{3} \mathrm{O}_{8}$. The twenty years preceding the year 2030 is viewed as the time of most critical economics when both the demand for and cost of fresh ore will be high.

Hybrids can affect the above picture by producing either fissile fuel or power. Which role for the hybrid is more advantageous? Hybrid production of fissile fuel would reduce, perhaps eliminate, the demand for fresh uranium ore as a source of fissile fuel for the thermal converters. Hybrid production of power could substantially reduce the number of thermal converters needed for power production without endangering the plutonium inventory needed for the fast breeders. Hybrids might even replace the fast breeders.

Now it may cost more to make electric power in a hybrid than in a thermal converter. In this case one is tempted to conclude that the design of the hybrid should favor fissile fuel production rather than power production. However, the coupling of mass flows, power generation, capital costs, fuel costs, etc. to thermal converters, breeders, hybrids, and fissile and fossil power plants creates a complex system. What strategy will result in a national power generation system of minimum cost is not at all obvious. One economic study by Deonigi 14,15 of the above situation showed that one could afford to build a more expensive hybrid plant if it produced $2000 \mathrm{~kg}$ of plutonium per jear and generated $1000 \mathrm{MW}(\mathrm{e})$ than if 
it produced for sale either no power and $4200 \mathrm{~kg}$ of plutonium per year or only power and no fissile fuel. In other words it appeared that neither the "fuel factory" nor the pure "power plant" version of the hybrid reactor was optimal.

In another economic study, similar to the above study, Deonigi and Engel 16 consider a national energy system into which pure fusion reactors are chosen to enter in the year 2010 and to eventually dominate the electric power generation by the year 2040. The mix of power sources at any time is determined by the continuous minimization of the cost of the national electric power system that is generating a prescribed history of electric power demand. Hybrids are introduced into this system about the year 2000 with different capital costs and different physical characteristics and produce different savings or benefits to the system. Hybrids are physically distinguished one from another through two characteristics: The annual yield of plutonium for sale per unit of thermal power generated and the plant efficiency, here defined as the ratio of electric: power for sale to the total thermal power generated.

One set of interesting results for a "zero "benefit" situation is summarized by Table 1. For comparison the "capitalized cost" of an LWR in this study is $\$ 310 / \mathrm{KWt}$. The "capitalized"cost" is a present value figure calculated from the plant cost plus the fuel costs accumulated over the plant life of 30 years. The capitalized costs in Table 1 are to be understood as target costs such the if a given hybrid, designed 
Table 1.

Capitalized Cost, $\$ / \mathrm{KWt}$

Annual Pu y.ield, kg/MWt

\begin{tabular}{c|c|c|}
\cline { 2 - 3 } Plant & & \\
\cline { 2 - 3 } Efficiency & 0.25 & 1.5 \\
\hline 0.40 & 440 & 720 \\
0.01 & 75 & 360 \\
\hline
\end{tabular}

to meet certain physical characteristics, can meet the indicated cost then the introduction of that hybrid into the national electric power system will generate a zero dollar savings over a prescribed number of years. If the cost of that hybrid can be reduced it will generate a positive dollar savings i.e. "benefit". If the cost of that hybrid fails to meet the target cost it will generate a negative benefit and will probably never penetrate the market.

The second line of Table 1 typifies a "fuel factory" that sells no electric power whereas the first line typifies a very efficient plant (low circulating power and high thermal efficiencies). There appears to be quite a variety of hybrid characteristics that have a zero benefit effect in this model of the national electric energy system. The differences from hybrid to hybrid are. what one can afford to spend in physically realizing them. It is also apparent from these numbers that either an increase in plant efficiency or an increase in the productivity of fissile "material will relax the cost limits that constrain the hybrid plant designer. The numbers confirm the intuition that the more efficient reactor will have the more attractive economics. 
This same information can be presented in terms of two characteristic hybrid blanket properties: the factor $M$. by which the blanket multiplies the energy deposited by the $14 \mathrm{MeV}$ neutron and the net number of atoms of fissile fuel, $F$, produced in the blanket by a single $14 \mathrm{MeV}$ neutron. Figure 1 shows several different hybrid blankets from the literature plotted as points in $M-F$ space. Where lines connect two plotted points the blanket properties have been varied by changing some internal ingredient. The fan of lines originating from the abscissa at $F=1.65$ are lines of constant capitalized cost and is a transformation of the data.summarized in Table 1. To make this transformation the hybrid reactor is modeled as shown in Fig. 2. It is assumed that the blanket produces plutonium and is the chief source of thermal power. We then have the following approximate relations for $x$, the annual production of plutonium in kilograms per MWt, and for the plant efficiency, Y:

$$
\begin{aligned}
& X=5.2 \cdot \frac{F}{M} \\
& Y=n_{t}-\frac{1.25}{n_{i} \mathrm{QM}} .
\end{aligned}
$$

(We have assumed the hybrid produces power $75 \%$ of the time.) The data of Table 1 . is well represented by the linear relation:

$$
\mathrm{C}=8.6+228 \mathrm{X}+938 \mathrm{Y} \quad \$ / \mathrm{KWt}
$$


Substituting for $X$ and $Y$ in eq. (3) we find

$$
M=\frac{1186\left(F-F^{*}\right)}{\left(C-C^{*}\right)}
$$

where:

$$
\begin{aligned}
& F *=\frac{0.989}{\eta_{i} Q} \\
& C *=8.6+938 \eta_{t} .
\end{aligned}
$$

Choosing $\left(\eta_{i} Q\right)=0.6$ and $\eta_{t}=0.333$ as typical of recent mirror hybrid studies 17,18 at the Lawrence Livermore Laboratory and a recent tokamak hybrid study ${ }^{19}$. at the Princeton Plasma physics Laboratory, eq. (4) produces the capitalized cost lines shown in Fig. 1. $\left(\mathrm{F}^{*}=1.65, \mathrm{C}^{*}=321\right)$ The mirror blanket lies on the line labelled with a 2 and the tokamak blankets lie on the lines labelled with a 1 . It is apparent that the mirror hybrid designer is allowed to build a more expensive device by favoring a fuel producing rather than a power producing blanket. Similarly the tokamak hybrid designer is in a contrary position being allowed to build a more expensive device if he favors a power producing rather than a fuel producing blanket. This conclusion rests on the angle between the capitalized cost lines and a line of blanket performance. This angle will be influenced by the location of the vertical capitalized cost line $C^{*}$. The location of the $C^{*}$ line is given by the value of $F^{*}$ that in turn is sensitive both 
to the "fusion gain", $\eta_{i} Q$, of the fusion device and to the relative value that the entire scenario for the national energy system places on the direct production of electric power versus the fueling. of thermal converters. This relative value is reflected in the relative magnitude of the coefficients of $x$ and $Y$ in eq. 3 . As the allowed capitalized cost increases more sharply with increasing plant efficiency or becomes insensitive to $\mathrm{Pu}$ production the magnitude of $\mathrm{F}^{*}$ will increase. For $F^{*}=2.0$ the. C* line would lie to the right nf 0.11 hint one of the blankets represented in Fig. 1 and consequently the genera 1 conclusion would be reached that higher values of. $M$ will invariably lẹad to a higher allowed capitalized cost. ." However a changing scenario for the "national energy system may produce allowable capitalized costs that are not so linearly related to the hybrid plant efficiency and fissile fuel productivity. In such a case the capitalized cost Iines in Fig. 1 may no longer display the neat fan-like pattern shown. Thus the issue for hybrid design of favoring fúel vs. power from a given blanket is not unambiguously resolved.

A dịferent economic assessment can be made by considering how a single hybrid plant can maximize itș revenue. What is the mix of fuel production and power production that will generate the largest revenue? This mix is available to the blanket designer through the choice of particular ingredients or geometry within the chosen style of blanket design. The range of choices will generate a certain curve in M-F space for the blanket. 
Chapin and Mills ${ }^{33}$ have shown quite generally that for a given price of electricity there is a certain price of fissile fuel below which the revenue of the hybrid plant will increase if more power and less fissile fuel is produced. If the price of fissile fuel exceeds this certain price, then the reverse will be true, namely, more revenue will be generated if less power and more fissile fuel is produced. The critical price for fuel is that price for which the revenue is indifferent to an increase in the blanket multiplication M. Because the revenue is linear in both $F$ and $M$, the indifference price of fuel exists if the $M-F$ plot for the blanket has a negative slope. Furthermore it is proportional to that slope. For the. blanket performance characterized by the lines labeled 1 in Fig. 1 the indifference price of fuel is about $\$ 250 /$ gm where one has assumed the price of electricity to be 20 mills per kilowatt-hour and a thermal efficiency for power conversion of 1/3. Similarly the indifference price for the blanket characterized by the line labeled 2 is about $\$ 525 / \mathrm{gm}$. This higher price reflects the steeper slope of this blanket's characteristic.

The conclusion here is that if one imagines the price of fissile fuel to be less than $\$ 250 / \mathrm{gm}$. Then to maximize revenue both blankets labeled 1 and 2 should be designed to maximize power production.

Still another approach to the economics of a hybrid is found in the analysis of a nuclear park by Lee, Bender and Moir. ${ }^{20}$ The nuclear park consists of .. one hybrid reactor and 
associated thermal converters. The net fissile material production of the hybrid provides the required fissile make-up for the thermal converters.: The net electric power produced by the nuclear park is the only source of revenue. The optimum hybrid reactor design produces the cheapest electric power for the public. 'Both the hybrid reactor and the thermal converters within the park are required to be run at an economic profit. The economic viability of the nuclear park is determined by the competitive price of electricity from other power sources as well ae the competitive price of flssile fuel originating outside the park.

A recent result ${ }^{17}$ of the mirror hybrid work using this. park model is an "electricity value" of $24.7 \mathrm{mills} / \mathrm{KW}-\mathrm{hr}$ and a plutonium price of $\$ 55 / \mathrm{gm}$. (By comparison the same study analyzed a hybrid with a thorium bearing blanket that produced U-233 for HTGR reactors. For this case the "electricity value" was $25.3 \mathrm{mi} 1 \mathrm{~s} / \mathrm{KW}-\mathrm{hr}$ and the price of $\mathrm{U}-233$ was $\$ 127 . / \mathrm{gm}$.$) . It$ would appear from these numbers that this mirror hybrid park is not economically viable at present, but definitely interesting for the future. The plutonium producing blanket used is represented in Fig. I by the line labelled with $a$ a 2 . The blanket is optimally run for $M$ about 11. The stated goal 23 is the production of fissile fuel at minimum cost. This result is inconsistent with the above argument for maximizing the revenue. The large discrepancy between the plutonium price of $\$ 55 / \mathrm{gm}$ and the indifference price of $\$ 525 / \mathrm{gm}$ for this blanket suggests that a more profitable operating point would be at 
higher values of $M$. The resolution of these different conclusions and the answer to the question: What is the hybrid role - power producer or fuel producer - is not clear.

A role for hybrid reactors totally unrelated to the production of power or fissile fuel is that of transmuting the radioactive toxic nuclear wastes from fission reactors to less harmful forms. It is a role that Lidsky refers to as "Augean" in his excellent discussion in reference (2). Of the nuclear wastes it is the long-lived ( 25,000 years) actinides that are the prime candidates for incorporation in a blanket surrounding a.fusion reactor. It is this fissioning (of the actinides) that enables one to call such a "fusion burner" a "hybrid."

The Westinghouse Fusion Power systems Department has just finished a conceptual design of a tokamak hybrid actinide burner $^{21}$. Their conclusion is that wall loadings approaching $10 \mathrm{MW} / \mathrm{m}^{2}$ are needed to be really effective and since such wal1. loadings are considered to be excessive, from a neutron damage point of view, there is a question if tokamaks are suited to such a task. 22

TECHNICAL DEVELOPMENT

The technical aspects of hybrid reactors fall naturally into distinct and somewhat separable parts: the fusion core and the surrounding blanket. As for the fusion core any of the schemes for a fusion reactor is a candidate for a hybrid reactor: tokamaks, mirrors, theta-pinches, laserṣ, e-beams, 
shocks, etc.: In particular the recent developments in neutral beam injection into mirrors and tokamaks has been so encouraging that larger devices are being actively planned. This effort is on the main line of the CTR program quite independent of hybrid issues. The Tokamak Fusion Test Reactor (TFTR) is being built at the Princeton plasma physics Laboratory and is expected to be in operation in 1981. It will be the largest tokamak in the world: The plasma can have a major and minor radius of $2.48 \mathrm{~m}$ and $0.85 \mathrm{~m}$ respectively and is driven by $20 \mathrm{MW}$ of $120 \mathrm{kV}$ deuterons ${ }^{24}$. By contrast hybrid reactors would require an order of magnitude more beam power and perhaps a factor of two in beam voltage.

In addition to an increase in required beam power, a commercial hybrid reactor will require the efficient production of neutral beams. The constraint of efficiency increases the difficulty: of successful neutral beam development inordinately 25,26 . The most serious loss of effictency fox the neutral beams arises in the process of converting the initial beam of energetic ions into a beam of neutral particles. The efficiency of neutralizing a $D+$ ion falls from about $50 \%$ at $100 \mathrm{kV}$ to about $20 \%$ at $200 \mathrm{kV} .27 \cdot$ It is therefore important to recover the energy of the unneutralized ions and schemes for directly converting this mechanical energy to electrical energy are under development particularly at the Lawrence Livermore Laboratory. In the event that beam injection energies exceed about $150 \mathrm{kV}$ it will probably become imperative, in the name of efficiency, to use negative ions as a beam source because of the relatively high ( $60 \%$ for D-) 
neutralizing efficiency for negative ions for all energies of interest. However, negative ion source development is still in its infancy.

Another critical point for the development of a suitable fusion source for a hybrid is the duty factor. Economic calculations frequently assume the power will be "on" $70-80 \%$ of the time. These numbers imply for pulsed operated devices a pulse duty factor in excess of 90\%. For tokamaks, if the "down time" between pulses is only a few seconds, the "burn time" must then be in excess of 100 seconds. Achievement of quasi-steady state operation is a prime experimental objective in tokamak research. The TFTR has a nominal pulse length of from 1 to 4 seconds. The scale up from 4 seconds in 1981 to, say, 100 seconds by 1986 will be a large and expensive step. This step will probably require superconducting coils to reduce the power requirements.

Other critical problems for magnetically confined systems are: the steady state operation of the beams, maintenance of plasma purity and the pumping of the throughput of injected particles.

Turning to blanket design the problem of designing a blanket for a hybrid is similar in many ways to the problem of designing a blanket for a pure fusion reactor. Common problems are: tritium breeding, cooling, structural integrity under neutron irradiation and high temperatures, assembly and disassembly - and by remote handling techniques - and so on. The problems unique lo the hybria blanket have to do with the 
breeding of "fissile material and the amplification of the incident neutron energy. These problems have been addressed in fission reactors in the context of a self sustaining neutron chain reaction. And it is just this feature of being self sustaining that separates the fission reactor core from the hybrid blanket, for in the hybrid the neutron reactions cannot be permitted to be self sustaining. This result is obtained not by adding neutron "poisons" to a fission reactor lattice (though the lithium needed to breed tritium is a neutron absorber) but by removing, in effect; part of the roactivity of the fission reactor lattice by adjusting the geometry or removing some of the fissile material. In place.. of the reactivity arising from $\mathrm{U}-233$ or $\mathrm{U}-235$ or $\mathrm{Pu}-239$ the reactivity of the $14 \mathrm{MeV}$ neutron is substituted. With this depletion of fissile material from the lattice comes a decrease in the energy producing capability of the blanket and, at the same time, an enhanced capability for the net breeding of fissile material. J. D. Lee's calculation 8 referred to in the Introduction reflects the original promise of the capabilities of a hybrid blanket.

The results of blanket" calculations displayed in Fig. 1 indicate the range of performance that can be expected. All the blankets shown produce at least one triton për $14 \mathrm{MeV}$ neutron. They all have tried to account for some structure although only the result from the Livermore studies (labeled with a 2) and the results from the PNL studies (labeled with 6 and 8) reflect a detailed thermal-hydraulics analysis and an 
attempt to address the mechanical constraints placed on the blanket by assembly with a specific fusion. device. A variety of coolants have been considered in these blanket designs reflecting the variety explored by fission reactors: molten salts, liquid metal, helium. It is notable that the coolant of the most common of all fission reactors, water, has been neglected. This is not an oversight but a decision reflecting a judgement of the difficulty of handling the expected large tritium content of the water and of coping with the chemical reactivity of water with lithium. This judgement may not go unchallenged. 34

\section{CONCLUDING REMARKS}

w)

The range of blanket performance appears to be large enough in M-F space to encompass "fuel factories" and stand alone power stations. It does not appear that the issue of what kind of a hybrid to build will be settled by the neutronics. The apprehension of the utilities to put one of these hybrids on line on the grid rather than safely off to one side making fuel for fission reactors will be a factor in the resolution of this issue. (Hopefully by the time a hybrid is ready to be operated by a utility it's plant availability will exceed 50\%.) It is easy to say that economics will decide the issue, but the question still remains, what are the "economics"? 
ACKNOWLEDGMENT

The author acknowledges many stimulating conversations with colleagues at the Princeton Plasma Physics Laboratory and with visitors Melville Clarke and Ehud Greenspan. This work was supported by. the Energy Research and Development Administration Contract E(11-1)-3073. 


\section{REFERENCES}

1. B. R. Leonard, Jr.., A Review of Fusion-Fission (Hybrid) Concepts, Nuclear Technology $\underline{20}, 161$ (1973).

2. L. M. Lidsky, Fission-Fusion Systems: Hybrid, Symbiotic, and Augean, Nuclear Fusion 15, 151 (1975).

3. F. Powel1, Proposal for a Driven Thermonuclear Reactor, California Research and Development Company Report LWS-24920 (Rev.) (1953).

4. L. Spitzer, Jr., Physics of Fully Ionized Gases (John Wiley and Sons, Inc., New York, 1962) 2nd ed., Chap. 5.

5. S. T. Butler and M. J. Buckingham, Energy Loss of a Fast Ion in a Plasma, Phys. Rev. 126, 1 (1962).

6. J. M. Dawson, H. P. Furth, and F. H. Tenney, Production of Thermonuclear Power by Non-Maxwellian Ions in a closed Magnetic Field Configuration, Phys. Rev. Letters 26, 1156 (1971).

7. R. F. Post, T. K. Fowler, J. Killeen, A. A. Mirin, A Concept for a Power Density Mirror Fusion Reactor, Phys. Rev. Letters $\underline{31}, 280$ (1973). 
8. J. D. Leer; Neutronics of Sub-Critical Fast Fission Blankets for D-T Fusion Reactors, 7th Intersociety Energy Conversion Engineering Conference Proceedings (American Chemical Society, Washington, D. C., 1972) pp. 1294-1298.

9. D. H. Imhoff, A Driven Thermonuclear Power Breeder, California Research Corporation Report CR-1 (1954).

10. D. L. Jaissby, ". Reactor Aspects of Counterstreaming-Ion Tokamak Plasmas, Nuclear Fusion 16, 15 (1976).

11. E. L. Draper, Jr., and S: J. Gage, The Fusion-Fission Breeder: Its Potential in a Fuel-Starved Thermal Reactor Economy, Technology of Controlled Thermonuclear. Fusion Experiments and the Engineering Aspects of Fusion Reactors, E. L. Draper, Jr., ed. (National Technical Information Service, Springfield, Virginia, 1974) Conf. 721111, pp. $132-143$.

12. J. R. Dietrich, Considerations of Importance to Decisions. on an Alternate Nuclear Program, Annals of Nuclear Energy (Pergamon Press, New York, 1975) Vol. 2 (Special. Issue) pp. 725-736.

1.3. H. A. Bethe, Fuel for LWR, Breeders and Near-Breeders, Annals of Nuclear Energy (Pergamon Press, New York, 1975) Vol. 2 (Special Issue) pp: 763-766. 
14. D. E. Deonigi, The Potential Role of Fission-Fusion Systems in the Electric Economy, Trans. Am. Nucl. Soc. $\underline{21}, 58$ (1975).

15. Conceptual Fusion-Fission Energy System, S. L. Bogart, ed., U.S. Energy Research and Development Administration Report ERDA-4 (1974).

16. D. E. Deonigi and R. L. Engel, The Economics of Fusion-Fission Systems, Proceedings of the US-USSR Symposium on Fusion-Fission Hybrid Reactors, Lawrence Livermore Laboratory, July 13-16, 1976, to be published; also Battelle Northwest Laboratory BNWL-SA-5876 (1976).

17. D. J. Bender and J. D. Lee, The Potential for Fissile Breeding with the Fusion-Fission Hybrid Reactor, Trans. Am. Nucl. Soc. $\underline{23}, 24$ (1976). Also Lawrence Livermore Laboratory Report UCRL-77887, (1976).

18. R. W. Moir et al., Progress on the Conceptual Design of a Mirror Hybrid Fusion-Fission Reactor, Lawrence Livermore Laboratory Report UCRL-51797 (1975).

19. F. H. Tenney, A Tokamak Hybrid Study, Proceedings of the US-USSR Symposium on Fusion-Fission. Hybrid Reactors, Lawrence Livermore Laboratory, July 13-16, 1976, to be published; also Princeton Physics Laboratory Report PPPL 1284 (1976). 
20. J. D. Lee, D. J. Bender, R. W. Moir, Optimizing the Mirror (Fusion-Fission) Hybrid Reactor for Plutonium Production, Trans. Am. Nucl. Soc. $\underline{22}$, 11 (1975). Also Lawrence Livermore Laboratory Report UCRL-76986 (1975).

21. R. P. Rose et al., Fusịon-Driven Actinide Burner Design Study, Westinghouse Electric Corporation Report WFPS-TME-033 (1976).

22. R. P. Rose, Tokamak-Actinido Burnor Dcaign Dtudy, Proceedings of the US-USSR Symposium on Fusion-Fission Hybrid Reactors, to be published.

23. R. W. Moir et al., Mirror Reactor Studies, to be published in Proceedings of the 6th International Conference on P.lasma Physics and Controlled Nuclear Fusion Research; also Lawrence Livermore Laboratory Report UCRL-78122 (1976).

24. Tokamak Fusion Test Reactor, Final Conceptual Design, Princeton: Plasma Physics Laboratory Report PPPL-1275 (1976).

25. See Ref. 18, Sect. 9 .

26. J. Hovingh and R. W. Moir, Efficiency of Injection of Neutral Beams into Thermonuclear Reactions, Nuclear Fusion 14, 629 (1974). 
27. K. H. Berkner, R. B. Pyle, J. W. Stearns, Intense, Mixed-Energy Hydrogen Beams for CTR Injection, Nuclear Fusion 15, 249 (1975).

28. J. Maniscalco, Fusion-Fission Hybrid Concepts for Laser-Induced Fusion, Nuclear Technology 28, 98 (1976).

29. W. C. Wolkenhauer, B. R. Leonard, Jr., A. M. Sutey, R. W. Moir, Conceptual Design of a Fusion-Fission Hybrid Reactor Based on a Mirror Fusion Reactor with a Subcritical Gas-Cooled Fission Blanket, Proceedings of the First Topical Meeting on the Technology of Controlled Nuclear Fusion, G. R. Hopkins, ed. (National Technical Information Service, Springfield, Virginia, 1974) Conf-740402, Vol. I, pp. 238-255.

30. T. G. Frank, Hybrid Reactor Concepts, Proceedings of the US-USSR Symposium ọ Fusion-Fission Hybrid Reactors, Lawrence Livermore Laboratory, July 13-16, 1976, to be published.

31. I. N. Golovin, Developments Related to Construction of Tokamak-Based Thermonuclear Reactors, U.S. Energy Research and Development Administration Report ERDA-tr-66 (1975).

32. A. G. Cook and J. A. Maniscalco, Uranium-233 Breeding and Neutrun. Multiplying Blankets for Fusion Reactors, Nuclear Technology $\underline{30}, 5$ (1976). 
33. D. L. Chapin and R. G. Mills, Optimization of Fusion-Driven Fissioning Systems, Proceedings of the US-USSR Symposium on Fusion-Fission Hybrid Reactors, Lawrence Livermore Laboratory, July 13-16, 1976, to be published.

34. E. Greenspan, Natural-Uranium Light-Water Breeding Hybrid Reactors, Proceedings of the Second Topical Meeting on the Technology of Controlled Nuclear. Fusion, Richland, Washington, Sept. 21-23, 1976, to be published. 


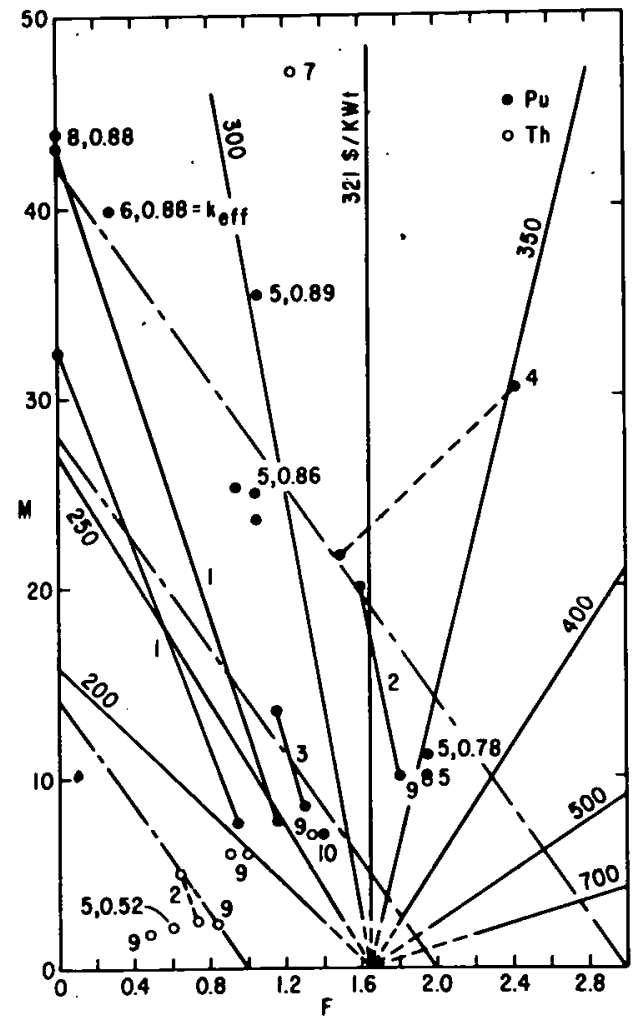

764584

Fig. 1. Blanket energy multiplication $M$ versus $F$, the net number of fissile fuel atoms produced per $14 \mathrm{MeV}$ neutron, for a number for blanket designs. Also shown are constant cost lines from Equation 4. The blanket label - reference number correlations are: 1-19\&.33, 2-23, 3-18, 4-8, 5-28, 6-29, 7-30, $8-2,9-32,10-31$.

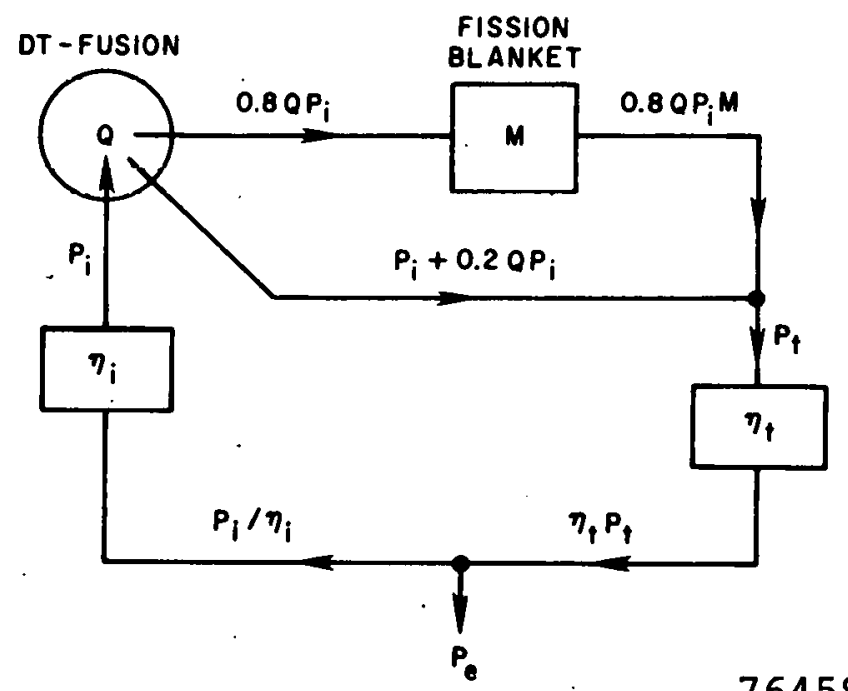

764583

Fig. 2. Model of power flow in hybrid reactor. 